\title{
Membangkitkan Minat Jemaat Dalam Menyanyikan Nyayian Kemenangan Iman Di Gereja Kemah Injil Indonesia Rehobot Mamuju Utara
}

\author{
Damri Apriyono, Rohani Siahaan
}

\begin{abstract}
Abstrak
Adapun yang menjadi tujuan dari penulisan ini adalah menjelaskan mengapa Nyanyian Kemenangan Iman kurang diminati dalam ibadah gereja sekarang terutama dalam Gereja Kemah Injil Indonesia. Yang menjadi ide utama penulis mengambil judul ini, karena penulis melihat beberapa tahun terakhir ini Nyanyian Kemenangan Iman sudah kurang diminati dalam ibadah gereja terutama bagi kaum muda. Dalam karya tulis ini yang menjadi fokus utama adalah Nyanyian Kemenangan Iman serta yang menjadi konsentrasi dalam penulisan ini adalah bagaimana mengembalikan minat jemaat terutama kaum muda dalam menyanyikan Nyanyian Kemenangan Iman dalam ibadah gereja. Solusi yang dipakai dalam penulisan karya ilmiah ini adalah gereja harus merevisi kembali Nyanyian Kemenangan Iman dari segi struktur kata nyanyian tersebut, agar jemaat atau kaum muda dapat mengerti isi dari Nyanyian Kemenangan Iman. Kesimpulannya adalah dengan menghadirkan kembali Nyanyian Kemenangan Iman ke dalam ibadah gereja serta melakukan perbandingan antara kesulitan dan kemudahan nyanyian kontemporer dan nyanyian Kemenangan Iman dalam ibadah gereja.
\end{abstract}

Kata-kata kunci: Minat Bernyanyi, Nyanyian Kemenangan Iman, GKII Rehobot Mamuju Utara

\section{Pendahuluan}

\section{Latar Belakang Masalah}

Berbicara tentang bernyanyi bukan lagi hal yang lazim didengar, bernyanyi sudah menjadi bagian dari setiap orang. Menyanyi adalah melantunkan suara dengan nada-nada yang beraturan, biasanya menyanyi diiringi dengan alat musik, baik itu menyanyi secara sendirian maupun menyanyi dalam kelompok, engan menyanyi juga dapat membuka kembali kenangan atau momen-momen lama yang jarang diingat. Bakat menyanyi pada setiap orang berbeda-beda, tapi kalau kita mau belajar pasti dapat menonjolkan kemampuan menyanyi tersebut sehingga dapat menghibur orang lain atau minimal diri sendiri. Menyanyi merupakan bentuk ekspresi musik yang paling pribadi. Selain itu, menyanyi juga memberikan sebuah wadah bagi jalur pengungkapan emosi bagi sebagian besar orang dibandingkan dengan yang diberikan oleh musik instrumental. ${ }^{1}$ Dalam pandangan masyarakat umum, menyanyi adalah sebagian dari aktivitas yang dapat dilakukan setiap saat,

${ }^{1}$ Djohan, Psikologi Musik (Yogyakarta: Penerbit Buku Baik, 2003) 
tanpa memiliki teknik vokal atau keterampilan yang mendasar. ${ }^{2}$ Seorang yang memiliki gairah yang besar untuk menjadi seorang penyanyi dapat menciptakan dunianya sendiri. ${ }^{3}$ Artinya jika seorang yang memiliki minat bernyanyi yang baik bukan saja dapat menciptakan suasana yang lebih spektakuler. Hal ini akan sangat baik jika diterapkan ke dalam ibadah gereja.

Tidak semua orang suka bernyanyi atau berminat untuk bernyanyi. Banyak faktor yang menyebabkan orang tidak minat bernyanyi seperti tidak mempunyai bakat menyanyi, tidak mengetahui lagu, tidak fasih dalam berbahasa dan ketika kondisi tubuh sakit menyebabkan suasana hati tidak berminat untuk bernyanyi. Salah satu hal ini juga yang menyebabkan jemaat tidak tidak berminat untuk menyanyikan Nyanyian Kemenangan Iman karena tidak mengetahui ragam lagu sehingga cenderung menyanyikan lagu yang lebih sering didengar.

Nyanyian ini sudah menjadi bagian dari liturgi ibadah dan menjadi sumber utama nyanyian jemaat yang digunakan oleh seluruh Gereja Kemah Injil Indonesia hingga pada pelosok negeri. Penggunaan Nyanyian Kemenangan Iman sebagai sumber nyanyian ibadah sudah ada sejak berdirinya Gereja Kemah Injil di Indonesia, tidak terkecuali di GKII jemaat Rehobot Mamuju Utara Sulawesi Barat.

Nyanyian Kemenangan Iman di GKII Jemaat Rehobot Mamuju Utara Sulawesi Barat sudah digunakan sejak berdirinya gereja tersebut. Nyanyian ini secara tidak langsung telah mampu membangun iman jemaat serta memberikan semangat untuk terus memuji Tuhan dan berkarya bagi Tuhan. Tetapi, seiring perkembangan zaman, dan dengan maraknya nyanyian yang dihasilkan oleh industri musik rohani, maka secara tidak langsung hal ini berimbas ke dalam gereja-gereja Kemah Injil yang ada di Indonesia, termasuk GKII Rehobot Mamuju Utara. Jemaat mulai tertarik menyanyikan lagu-lagu baru di luar Nyanyian Kemenangan Iman, terutama kaum muda dalam jemaat, lagu-lagu baru lebih disukai ketimbang lagu-lagu dari Nyanyian Kemenangan Iman. Sehingga minat menyanyikan Nyanyian Kemenangan Iman dalam jemaat menjadi berkurang. "Nyatanya, bernyanyi merupakan salah satu unsur menciptakan situasi yang riang dan membahagiakan"

Perubahan ini menimbulkan banyaknya jemaat dari kalangan orang tua kurang menerima kehadiran nyanyian-nyanyian baru. Di samping lirik lagu yang masih asing di telinga, gaya dan bentuk lagu pun sulit dipahami sehingga lagu-lagu baru ini kurang dapat diterima. Memang dapat dipahami, sebagian besar Jemaat Rehobot adalah kaum awam, jadi adanya lagu baru seperti tidak menjadi masalah, yang penting lagu tersebut musiknya enak didengar dan energik, apalagi kandungan teologi maupun alkitabiah lagu tidak lagi menjadi perhatiannya.

Banyaknya hadir lagu-lagu baru tidak dapat dihindari oleh gereja, tetapi gereja perlu mengkondisikan penggunaannya, seperti: mempelajari isi syair dan tematik alkitabiahnya. Hal ini dikarenakan, sering kali lagu-lagu baru yang dihasilkan industri musik kurang memiliki dasar alkitabiah yang benar, walaupun musikalitasnya cukup baik.

\footnotetext{
${ }^{2}$ Soeharto, A. H. Membina Paduan Suara dan Grup Vokal. (Jakarta: PT Gramedia, 1982)

${ }^{3}$ Rudy MY, Panduan Olah Vokal: Meniti Karier Sebagai Penyanyi Profesional (Ciganjur: Buku Kita, 2008), 10.

${ }^{4}$ Feny Rahmawati, "Penggunaan Metode Menyanyi Dalam Rangka Meningkatkan Motivasi Belajar Pada Pembelajaran Bahasa Arab Bagi Siswa Kelas I SD Ta'mirul Islam.” (Skripsi S.Pd.I, Universitas Muhammadiyah Surakarta, 2013), 21.
} 
Untuk menilai sebuah nyanyian yang digolongkan sebagai nyanyian umat atau nyanyian jemaat di gereja, dibutuhkan keterlibatan banyak orang sesuai dengan bidang masing-masing seperti; musisi, ahli bahasa dan ahli teologi. ${ }^{5}$ Artinya ialah, supaya dapat membangkitkan minat jemaat untuk memahami makna yang terkandung dalam Nyanyian Kemenangan Iman.

Dengan demikian kerja sama yang baik antar masing-masing bidang dapat menjelaskan baik dari segi musiknya, tata bahasanya serta makna teologis yang terkandung dalam Nyanyian Kemenangan Iman tersebut. Dengan cara ini diharapkan akan membantu jemaat meminati Nyanyian Kemenangan Iman sekaligus menjadi satu jalan untuk membatasi penggunaan lagu-lagu rohani baru di dalam ibadah jemaat terutama di jemaat GKII Rehobot Mamuju Utara.

\section{Pokok Masalah}

Berdasarkan latar belakang masalah yang telah diuraikan yang di atas, maka pokok masalah yang menjadi fokus penulisan karya ilmiah ini ialah, bagaimana membangkitkan minat jemaat di GKII Rehobot Mamuju Utara untuk menyanyikan Nyanyian Kemenangan Iman?

\section{Tujuan Penelitian}

Tujuan dari karya ilmiah ini adalah, agar Jemaat GKII Rehobot Mamuju Utara kembali berminat dan menggunakan Nyanyian Kemenangan Iman sebagai nyanyian utama dalam ibadah.

\section{Manfaat Penelitian}

Pertama, memotivasi penulis untuk mencintai dan lebih mendalami keindahan Nyanyian Kemenangan Iman

Kedua, memberikan pemahaman kepada jemaat GKII Rehobot bahwa Nyanyian kemangan Iman telah teruji baik dari segi musik, melodi, syair serta makna teologi yang terkandung di dalamnya.

Ketiga, untuk memenuhi salah satu persyaratan dalam menyelesaikan program strata satu (S1) di Sekolah Tinggi Teologia Jaffray Makassar.

\section{Metode Penelitian}

Dalam penulisan karya ilmiah ini, metode penelitian kuantitatif yang digunakan oleh penulis adalah:

Pertama, penelitian kepustakaan, yaitu dengan membaca buku-buku yang berhubungan dengan karya ilmiah ini.

Kedua, penelitian lapangan, yaitu dengan hadir langsung di gereja tersebut dan melakukan wawancara baik tatap muka maupun melalui via telepon kepada jemaat GKII Rehobot sesuai dengan pokok masalah dari karya ilmiah ini.

\section{Batasan Penelitian}

Penulisan karya ilmiah ini hanya berfokus pada: upaya membangkitkan minat Jemaat GKII Rehobot Mamuju Utara untuk menyanyikan Nyanyian Kemenangan Iman dalam ibadah.

\footnotetext{
${ }^{5}$ Rohani Siahaan, Diktat Himnodi (Makassar: Sekolah Tinggi Teologia Jaffray makassar, 2006), 8. Belum dipublikasikan.
} 


\section{Kesimpulan}

Berdasarkan penulisan karya ilmiah yang dibahas di bab-bab sebelumnya tentang Membangkitkan Minat Jemaat Dalam Menyanyikan Nyanyian Kemenangan Iman, Maka penulis penulis menarik kesimpulan sebagai berikut:

Pertama, dengan adanya Nyanyian Kemenangan Iman sebagai sumber nyanyian jemaat serta membangkitkan semangat jemaat untuk menyanyikan dan memuji Tuhan.

Kedua, dengan adanya upaya gereja untuk merevisi setruktur kata Nyanyian Kemenangan Iman dapat membantu jemaat atau kaum muda lebih mencintai Kemenangan Iman.

Ketiga, memberikan pemahaman kepada jemaat terutama jemaat dari kaum muda tentang makna dan teologi dari Nyanyian Kemenangan Iman supaya terus dinyanyikan dalam ibadah.

\section{Kepustakaan}

Ali, Mohamad. Penelitian Kependidikan Prosedur dan Strategi. Bandung: Angkasa, 1995 Benson, Clarense H. Pengantar Perjanjian Lama Puisi dan Nubuat. Malang: Gandum Mas, 1983.

Charlie, Peacock, Moly Nicholas. Cross At The Roads. United States of America: WaterBrook Press, 2004.

Crow, Lester D., and Alice Crow. An Out Line Of General Psychology. New York: Lithfe Field Adam and co, 1963.

Dyrness, William. Tema-tema Dalam Perjanjian Lama. Malang: Gandum Mas, 2004.

Djohan. Psikologi Musik. Yogyakarta: Penerbit Buku Baik, 2003.

Dop, H. A. van. Menggubah Nyanyian Jemaat. Jakarta: BPK Gunung Mulia, 1984.

Paul W. Wohlgemuth. Rethinking Church Music. Carol stream Illnois: Hope Publishing Company, 1981.

Kamus Besar Bahasa Indonesia. Jakarta: Balai Pustaka, 2001.

Karina, Andjani. Apa Itu Musik. Kajian Tentang Sunyi dan Bunyi Berdasarkan 4'33" karya John Cage. Serpong: Gajah Hidup, 2014.

Mark, Allan Powel. Encyclopedia Of Contemporary Cristian Music. United States of America: Peabody, Massachuesetts, 2002.

Robert, Gregg, Gary W. McDonogh, and Cindy H. Wong, Encyclopaedia of Contemporary American Culture. Routledge, 2005.

Sitompul, Binsar. 1986. Paduan Suara dan Pemimpinnya. Jakarta: BPK. Gunung Mulia, 1986.

Siahaan, Rohani. Diktat Himnodi. Makassar: STT Jaffray makassar, 2006. Belum dipublikasikan.

Siahaan, Rohani. "Jurnal Analisis Pengaruh Nyanyian Jemaat Terhadap Kualitas Ibadah Gereja Protestan di Indonesia Bagian Barat (GPIB) Jemaat Bukit Zaitun Makassar." Jurnal Jaffray. 11, No. 2 (Oktober 2013): 140-164. 
Sugiyono. Metode Penelitian Kuantitatif dan Kombinasi (mixedmethods). Bandung: Alfabeta 2014.

Soeharto, A. H. Membina Paduan Suara dan Grup Vokal. Jakarta: PT Gramedia, 1982.

Tison, Jermia Djadi. "Pengajaran Tentang Ibadah Berdasarkan Surat Ibrani 10:19-25 Dan Implementasinya Dalam Masa Kehidupan Orang Percaya Pada Masa Kini." Jurnal $\begin{array}{lllllll}\text { Jaffray 11, No.1 (2013):37-66. Diakses } 26 & \text { Juli } 2018 .\end{array}$ http://ojs.sttjaffray.ac.id/index.php/JJV71/article/download/67/pdf_53

Watkins, Calvert. The American Heritage Dictionary of Indo-European Roots. Oxford: Claredon Press, 1980.

Wijaya, Hengki (ed.). Metodologi Penelitian Pendidikan Teologi. Makassar: Sekolah Tinggi Teologia Jaffray, 2016.

Y., Rudy M. Panduan Olah Vokal: Meniti KarierSebagai Penyanyi Profesional. Ciganjur: Buku Kita, 2008. 